\title{
Violence against Women- Focus on Domestic Violence
}

\author{
Sunita Sapkota
}

BPH, 21st Batch, IOM

Violence against women (VAW) is a manifestation of historically unequal power relations between men and women, which have led to domination over and discrimination against women by men and to the prevention of the full advancement of women (The UN Declaration on the Elimination of VAW, 1993).

Violence against women and girls is one of the most widespread violations of human rights. (VAW) has been recognized globally as a public health problem which violates human rights and incurs substantial social, economic and health costs. It can include physical, sexual, psychological and economic abuse cutting across boundaries of culture, class, education, income, ethnicity, geography and age. Globally, six out of every ten women experience physical or sexual violence.

In Nepal, violence against women started being openly discussed and addressed only in the last decade. The general taboo of not accepting this form of violence was related to strong patriarchal society and limited freedom of expression of such social evils. It has therefore been openly discussed as the most common form of gender based violence as domestic violence, or gender based violence in families.

Domestic violence includes physical acts of violence within the family including sexual coercion by the husband, physical threats, and psychological abuse and controlling actions such as enforcing physical isolation and controlling access to information and services.

-(WHO, 1997)

The domestic violence can take the form of pushing, hitting, choking, slapping, kicking, burning or stabbing. Though, violence occurs in different forms and settings including workplace, school and community, violence at home 'domestic violence' is considered the most pervasive form. Domestic violence is widespread problem in Nepal. It is any kind of gender based violence that occurs within the domain of house. The prevalence of domestic violence is open secret; however Nepal doesn't have separate law to address domestic violence. Violence in the domestic sphere is usually perpetrated by males who are, or who

have been, in positions of trust and intimacy and power husbands, boyfriends, fathers, fathers-in-law, stepfathers, brothers, uncles, sons, or other relatives. Domestic violence is in most cases violence perpetrated by men against women. Women are victims of violence in approximately $95 \%$ of the cases of domestic violence. Domestic violence is also known as Family Violence.

\section{Extent of Problem}

\section{Global situation}

According to the Family Violence Prevention Fund (FVPF), one in every three women in the world has experienced sexual, physical, emotional or other abuse in her lifetime. Statistics on the prevalence of the problem indicate that domestic violence is a worldwide epidemic. Studies show that between one quarter and one half of all women in the world have been abused by intimate partners. Worldwide, $40-70 \%$ of all female murder victims are killed by an intimate partner. Many people view domestic violence as exclusively part of certain ethnic or racial communities, or as unique to certain classes, within their societies. The WHO also reports that studies from a range of countries show that $40-70 \%$ of female murder victims were killed by an intimate partner.

\section{In Nepal,}

Although Nepal's decade long conflict has ended, every year tens of thousands of women in the country still experience violence. Of the total incidence of violence against women, domestic violence constitutes over $80 \%$. Among the various causes of domestic violence, dowryrelated hostilities, polygamy, assaults on women accused of being witches, and disputes involving properties are common (National Women Commission).

In about, $80 \%$ of cases, the perpetrators are no stranger to the woman but a member of her own family. This indicates that even the home is not a safe place for women. Social relations of power place women in a subordinate position, giving many women few rights in the family, community and society in general.

Historically, violence against women and girls has been in existence in Nepali society. A situation analysis conducted by SAATHI (1997) on violence against women in Nepal revealed that $93 \%$ had exposed to mental and emotional torture, $82 \%$ were beaten, $30 \%$ raped, $28 \%$ forced in to prostitution, $64 \%$ reported polygamy. The maternal mortality study conducted by Family Health (1998), revealed that higher suicide rate among women of reproductive age group. Another report from Nepal reported that maternal mortality accounts for the highest number of women's deaths each year, followed by suicide. Almost five hundred cases of suicide were reported to Nepal police in 2003-2004 (Asia foundation, 2004). The census recorded half million women living in polygamous marriages (DFID), and other studies have shown that polygamy is a serious cause of depression for women in Nepal (SATHHI 2001). In one study, 100\% of 
respondents said they knew of girls between the ages of 11-15 who had suffered sexual abuse (SATHHI, 1997).

A reference kit on violence against women and girls on south Asia (2001) has presented the data of Nepal on domestic violence, which is faced by married women.

$1 \quad$ In a period of 6 month from June to December 2000 , the women's right helps line in

$1 \quad$ Katmandu received 624 calls from women. Out of these call, 107 were from battered wives.

$158 \%$ of the domestic violence cases reported daily abuse.

$1 \quad 77 \%$ of the violence perpetrators were family members, and

$166 \%$ of the women endured verbal abuse, $61 \%$ sentimental torture and $33 \%$ emotional torture etc.

The main reason cited for domestic violence are dowry related issues, infertility, alcoholism and suspicious habit of husbands etc.

\section{Nature of Domestic Violence}

Domestic violence has distinct character as opposed to other types of violent crime. It can be characterised by at least five features:

1. It is perpetuated by someone else close to victim, usually her partner or ex-partner

2. It happens in intimate settings which are presumed by society to be sites of support and care

3. It is a recurring form of abuse generally characterized by a cycle of violence.

4. The abusers use domestic violence to control and coerce the victim.

5. The abuse has profound emotional and psychological effects in the victim, who often believes that she is to blame for the violence.

\section{Responsible factors for Domestic Violence}

1 Patriarchal society

1 Discriminatory laws (There are 118 legal provisions, 67 schedules spread in different law and the constitution that is discriminatory against women)

1 Social Practices

1 Culture, religion and tradition

1 Portrayal of women by media

1 Economic dependency

1 Lack of awareness

$1 \quad$ Lack of skills and employment

$1 \quad$ Traditional up-bringing

o (Women are brought up in such a situation that they have believed that they are inferior to men. They have seen their mothers and sisters suffering from violence)

$1 \quad$ Vicious cycle of poverty

o (Girls have to look after their younger brother and sister in one hand and in another their parents can't afford for their schooling)

\section{Types of Domestic Violence}

It is categorised into five types:

\section{Physical Abuse}

Abuse committed with an objective of giving physical pain is physical abuse. This includes slapping, beating, arm twisting, stabbing, strangling, burning, choking, kicking, and threatening with a weapon, murder, traditional harmful practices like Female Genital Mutilation (FGM) and widowhood abuse

\section{Sexual Abuse}

Those abuse which occurs due to women's incompetency in fulfilling the sexual desires of men. This includes coerced sex through threats, intimidation or physical force, forced prostitution or any unwanted sexual act.

\section{Psychological Abuse}

It includes all intimidating and threatening behaviour, persecution, abandonment or threats of abandonment, confinement, surveillance, verbal abuse and mental torture.

\section{Emotional Abuse}

Emotional abuse includes causing fear, shame, public embarrassment, continued threats and taunts, isolation and humiliation.

\section{Economic Abuse}

It includes acts such as denial of funds, exploitation, controlling access to healthcare, food, basic necessities and denial of rightful income.

\section{Forms of Domestic Violence}

Domestic violence is undoubtedly the most prevalent form of violence against women and girls. It is seen broadly as any act of violence within house such as differential treatment of girls, wife-beating, torture of daughter in-law and neglect and torment of widowed women in the family. The various forms of domestic violence as seen in our society is as;

1 Son preference leading to female foeticide

$1 \quad$ Battering of mother during pregnancy

$1 \quad$ Neglect and marginal treatment of girls

1 Confinement within household

1 Child marriage 
$1 \quad$ Dowry related abuses or deaths

1 Marital Rape

1 Control over reproductive roles of women

\section{Health Consequences}

$1 \quad$ Injuries: Physical and sexual abuse by a partner is closely associated with injuries. Violence by an intimate partner is the leading cause of non-fatal injuries to women in the USA.

1 Death: Deaths from violence against women include honour killings (by families for cultural reasons); suicide; female infanticide (murder of infant girls); and maternal death from unsafe abortion.

$1 \quad$ Sexual and reproductive health: Violence against women is associated with sexually transmitted infections such as HIV/AIDS, unintended pregnancies, gynaecological problems, induced abortions, and adverse pregnancy outcomes, including miscarriage, low birth weight and foetal death.

1 Risky behaviours: Sexual abuse as a child is associated with higher rates of sexual risk-taking (such as first sex at an early age, multiple partners and unprotected sex), substance use, and additional victimization. Each of these behaviours increases risks of health problems.

$1 \quad$ Mental health: Violence and abuse increase risk of depression, post-traumatic stress disorder, sleep difficulties, eating disorders and emotional distress.

$1 \quad$ Physical health: Abuse can result in many health problems, including headaches, back pain, abdominal pain, fibromyalgia, gastrointestinal disorders, limited mobility, and poor overall health.

\section{Challenges for combating Domestic Violence}

1. Lack of research and studies

2. Discriminatory laws against women

(Guardianship laws discriminate in favor of men, making it impossible for women to break away from their relationship with men. Domicile laws relating to nationality and immigration also create women's dependency on men for economic resources and citizenship)

3. Poor reporting of the cases

4. Lack of shelters for victims of Domestic violence

5. Political apathy

6. Gender stereotypes roles

(The gender stereotypes roles of men and women in family and society further reinforces the inferior position of women and hold women inside the domain of household chores. This influence women's capacity to raise their voice against their exploitation)

\section{How can Domestic Violence be addressed?}

1. Need of separate legislation to address domestic violence

2. Fulfilment of international commitment

(Policy makers and lawmakers should always use the ratified international treaties as a guideline for making new policy and enacting laws)

3. Repeal discriminatory laws against women

4. Establish family courts (in every district to enable women to report cases)

5. Gender sensitization training

6. Rehabilitation/shelters

7. Preventive Approaches

1 Advocacy to inform the public as well as judiciary, executive and legislative agencies)

$1 \quad$ Address gender disparities

1 Increase economic opportunities for women

1 Establish community service system (Community support services-victim seek assistance from family, health workers, women's organization)

$1 \quad$ Interventions for changing social values

$1 \quad$ Education through media

1 Coordination among various agencies (linkage among police, NGO, civil society \& government bodies to provide assistance to victim)

\section{Political commitment}

1 Need of research (Study on incidence of family violence to identify dimension and magnitude as well as study on impact of NGO and government initiatives to address domestic violence is to be focused)

\section{Conclusion}

Domestic violence is the most pervasive form of violence against women. Domestic violence is an universal phenomenon prevailing everywhere from the past to till date, may it be a developed countries or the developing one.

So, the need is to internalize domestic violence as gross human rights violation of women, which requires momentum from every sphere of the society including, legislative, judiciary, executives, civil societies and from the general people to take initiatives from their own level.

\section{References}

1. Domestic Violence against women and girls.UNICEF, june 2000

2. Pradhananga, BR. Domestic Violence against women in Nepal: concept, history and existing Laws

3. WHO, fact sheet, November 2009 